\title{
Evaluating the Lumbar Nerve Root Stretching using Straight Leg Raising Technique A cost effective treatment option for patients of lumbar disc disease
}

\section{Amit Chaitanya ${ }^{1}$, Rishabh Kumar Rana²}

${ }^{1}$ Assistant Professor, Department of Physical Medicine and Rehabilitation, Rajendra Institute of Medical Sciences, Ranchi;

${ }^{2}$ Assistant Professor, Department of Preventive and Social Medicine, Patliputra Medical College and Hospital, Dhanbad

\begin{tabular}{|c|c|c|c|c|c|c|c|}
\hline Abstract & Introduction & Methodology & Results & Conclusion & References & Citation & oles / Figures \\
\hline \multicolumn{8}{|c|}{ orresponding Author } \\
\hline \multicolumn{7}{|c|}{$\begin{array}{l}\text { Dr Rishabh Kumar Rana, Assistant Professor, Department of Preventive and Social Medicine, Patliputra } \\
\text { Medical College and Hospital , Dhanbad, Jharkhand - } 826005 \\
\text { E Mail ID: bakwasandsony@gmail.com }\end{array}$} & 回评回 \\
\hline
\end{tabular}

\section{Citation}

Chaitanya A, Rana RK. Evaluating the Lumbar Nerve Root Stretching using Straight Leg Raising Technique A cost effective treatment option for patients of lumbar disc disease. Indian J Comm Health. 2020;32(2):371-377.

Source of Funding: Nil Conflict of Interest: None declared

\section{Article Cycle}

Received: 07/04/2020; Revision: 15/05/2020; Accepted: 08/06/2020; Published: 30/06/2020

This work is licensed under a Creative Commons Attribution 4.0 International License.

\section{Abstract}

Background: Lumbar disc disease is one of the most important cause of lumbar radiculopathy. Even a normal healthy disc may rupture by sudden heavy load if it is beyond the tensile limit of annulus fibrous. The lumbo-sacral radicular pain due to lumbar disc herniation, is responsible for DALY loss in terms of work absenteeism and disability. For a developing country like ours it's a major health issue often ignored as patients don't require hospitalization. In a developing country a cost effective method which is not increasing any out of pocket expenditure for the patient for relief from the lumbar disc disease suffering must be hailed as a boon considering its effectiveness as well as feasibility of administration everywhere. Method Starting March 18 till Dec 19 records of patients coming as per our eligibility criteria after IEC clearance were evaluated for the effectiveness of straight leg raising technique with data being analyzed using the measures of central tendency and other appropriate tests. Results Out of 72 patients 69 achieved improvement in pain while 68 achieved improvement in their ability to move along. Conclusion Given the zero cost of exercise technique this technique is an easy to master technique. if larger studies can validate our findings this can be taken at grass root levels to bolster the health care systems and train front line health care service givers so that last mile beneficiary too gets the benefit and relief from chronic pain owing to lumbar disease.

\section{Keywords}

Lumbar Disc Disease; Jharkhand; Straight Leg raising technique; Cost effective

\section{Introduction}

Lumbar disc disease is one of the most important cause of lumbar radiculopathy. Even a normal healthy disc may rupture by sudden heavy load if it is beyond the tensile limit of annulus fibrous (1) Lumbar disc disease can also happen due to age related degeneration of disc. Degenerative loss of proteoglycans can cause decreased disc hydration and disc collapse. $(1,2)$ The neuropathic pain associated with lumbar disc disease is caused by combined effect of nerve root inflammation and ischaemia due to increased local pressure. $(1,3,4)$ Sitting for prolonged durations is now the commonest workplace posture due to advent and dependence on computers and laptop for almost all work (5) The intra discal pressure increases while sitting for prolonged durations.(6) Not only sitting for prolonged duration but other activities like heavy weight lifting, sudden trunk rotation with forward bending, jerks (vehicle driving) are some of the occupational hazards responsible for low back pain and lumbar disc diseases. $(7,8)$ The lumbo-sacral radicular pain due to lumbar disc herniation, is responsible for DALY loss in terms of work absenteeism and disability. For a developing country like ours it's a major health issue often ignored as patients don't require hospitalization. (9) In India there are various activities involving abnormal bending and twisting of spine. The religious postures, floor sitting, squatting are some of the prime examples. $(9,10)$ In patients of sciatica, continued conservative care can resolve pain and morbidity without surgery, but the possibility for delayed surgery after prolonged suffering 
from neuropathic pain is always there if the conservative care fails. (11)

Of the available treatments, Hamstring stretching and nerve mobilization both are effective in lumbar radiculopathy with nerve mobilization being accepted as superior method.(12)

These techniques often require equipment, trained manpower and advances set ups, which patients coming in our OPDs cannot afford. Studies have documented in cases of nerve root compression the microcirculation is also compromised leading to nerve root oedema. It causes further increase in pressure on nerve. The technique used in this study is based on the principle of "Neuro dynamic techniques" which consist of short oscillatory movements that can disperse the fluid and decreases the pressure which improves the microcirculation of nerves. Evidence is there which has shown better results. (13)

It has been well documented that Lumbar disc prolapse is more among people living or working in areas of poor infrastructures. (14) Evidence also suggests that most of the times patients if unsupervised are not complaint with the therapy given to perform in most chronic conditions (15). Indian scenario is full of people still living close to or below poverty line and government hospitals are mostly thronged by patients who are not so well off. However, as the chronicity lingers on people again shy away from costly treatments. Back ache due to lumbar diseases are long time problems which plague persons for long periods and are hard to be managed.

So cost effectiveness of therapy for lumbar disc prolapse becomes very important in our present scenario. The lumbar nerve root stretching technique intended to being employed is designed considering these challenges and is home based, self-employable and free of cost. We have seen patients being treated by our Straight Leg raising technique which intend to use the lumbar nerve root stretching and want our method to get to the community settings as the methods of the exercise are easy to imply and if understood properly by medical officers these can be further imparted down the line to the front line health workers.

\section{Aims \& Objectives}

1. To evaluate effectiveness of lumbar nerve root stretching exercise using straight leg raising technique in conservative management of lumbar disc disease.

2. To collect the epidemiological data related to lumbar disc disease in Jharkhand.

3. To improve and modify ongoing conservative management of lumbar disc disease.

\section{Material \& Methods}

IEC Clearance - Study was conducted after clearance from the Institutional Ethical Committee.
Type of Study/Study design - A Retrospective record based observational descriptive study design was undertaken to analyze outcomes of the treatment given.

Study Setting -A Hospital Record Based Study was conducted on the patients who were treated in PMR Department and their records were evaluated to understand the effectiveness of treatment given, Rajendra Institute of Medical Sciences, Ranchi, and Jharkhand.

Study Period -Data analysis and conclusion required about three months.

Sample Size -The sample Size of study was based on the available records and patient flow of lumbar disc disease was seen to be around 70 around previous one and half year. Records were started taken from March 18 to Dec 19.

Data Collection -Collected clinical data was used as per hospital records consisting of assessment of pain severity by 10-point Visual Analogue Scale and assessment of functional impairment using Oswestry Disability Index (ODI).

Data analysis - Data thus collected was entered on excel template using MS Excel and analysis was done using SPSS version 22.0. Measure of central tendency like mean, mode etc. and appropriate statistical tests like Chi square, Paired t tests, and Logistic Regression analysis were done to interpret the results.

\section{Inclusion and Exclusion Criteria}

Inclusion Criteria- Records of patients that had complains of having unilateral or bilateral radiating pain in lower limb and also clinically and radiologically indicative of lumbar disc disease with nerve root compression were included.

Exclusion Criteria- Records of patients with Lumbar Disc disease associated with infective aetiology or associated severe trauma, vertebral body fracture/ ligament injury were excluded as they were not suitable for this technique of management.

Methods -All the patients had been advised bed rest, exercise and medicines according to their condition and severity of pain. Special attention had been paid in demonstration of exercises and patient education regarding the condition, the need of bed rest, the importance of correct body posture. All the patients had been advised to do lumbar nerve root stretching exercises using the principles of straight leg raising test from the very beginning of their management. This technique involved can be briefed in three basic steps

1. Patient should lie down straight on a flatbed in side lying position with the involved side up

2. Flex the lower limb at hip joint 30 to 60 degree depending on tolerance with knee in full extension place a pillow or folded blanket below distal third of leg.

3. After relaxing for few seconds perform full active and repeated ankle dorsiflexion and plantar flexion. If there is bilateral nerve root compression the 
manoeuvre was repeated on both side alternatively. In cases of weak ankle dorsiflexes nerve root stretching was achieved by repeated 20 degree flexion and full extension at knee with foot fixed in elevation via ankle foot orthosis. The above manoeuvre was to done as much as possible but within the limit of pain and patients had been asked to gradually increase the duration and schedule as per improvement in condition.

Outcome measures- The severity of pain and functional impairment was assessed by using Visual analogue 10point scale and Oswestry Disability Index scale at day 1 , after 10 to 15 days and at 25 to 35 days of management.

\section{Results}

Our record analysis gave us 72 individuals who were eligible to be included in our study. In our study we saw a mean age of 35 years (Table 1 ) with wide variations of age group. We had both males and females as study participants, with males $71.4 \%$ dominating in numbers than females. Most of the females were working as home makers while males mostly worked either as Army men or Drivers or Police professionals. A combined $57 \%$ of working male were working as Policemen, army men, farmers, drivers or labourers while rest $(21.42 \%)$ of male were office goers or students. (Table 1). Majority of patients were from low socioeconomic strata of the society and more than $50 \%$ were Hindus by religion. In our study group on probing their residences we found maximum from urban locality in Ranchi while rest were from varied locality outside Ranchi or outside state of Jharkhand. Maximum Majority were diagnosed as having Lumbar disc disease, they presented as having lumbar radiculopathy right side (54.3\%), lumbar radiculopathy left side $(32.9 \%)$ while $12.9 \%$ had lumbar radiculopathy of both side (Table 1). Among the available MRI data, the most common level of disc prolapsed was L4-5. However, many patients were having multilevel disc disease. On probing the exercise pattern along with rest pattern we came up with some details which suggests more females and males $>20 \%$ alike despite of having severe or chronic radiating pain were not doing the exercise in proper way or taking appropriate rest. (Table 1). We also asked for the duration of pain to ascertain the chronicity of pain in males and females alike. We found that majority of males were having pain of onset 1-30 days while some females were presenting with a pain which was as long as three years old. (Table 2 ) The $p$ values were obtained using chi square tests for association. We found our diagnosis to be significantly associated with sex and nature of work. We administered the VAS or Visual Analogue Scale to measure the pain intensity on the day our participants were evaluated and enrolled before any intervention and henceforth it will be mentioned as VAS on day 0 similarly ODI or Oswestry Disability Index was measured to ascertain the mobility of the participants and is mentioned as ODI scores for Day 0 (before intervention). After we explained the detailed process of the exercise and rest pattern to the patients we revaluated them on day 15 after 14 days of doing our exercise. VAS and ODI scores for Day 15 and similarly VAS and ODI scores on day 35 were taken after they came in our OPDs. It was recorded and a Paired T test were employed to evaluate the scores. (Table 3) \& (Table 4). The paired $T$ tests showed that the Treatment or intervention given was statistically of high significance. Legitimizing our therapy. A binary logistic regression model was run to ascertain predictors for improvement in Mobility and Pain as we had two nonresponders to treatment in context of pain relief and three non-responders to improvement in mobility. (Table 5) We can only see that Exercise and its continuation on 15th Day coupled with rest as directed on day 15 were good predictors along with the Measuring scales employed for measuring pain and mobility i.e. VAS and ODI on day 0 and 15. (Table 5)

\section{Discussion}

In our study we had more males which can be attributed to the societal pattern prevalent in Jharkhand state as has been evident in other studies done having a mixture of male and female as study participants done in eastern parts of India including Jharkhand or its other districts $(16,17)$. Like other studies males were from professions demanding labour with little time to give rest to their tiring bodies. $(12,13,14)$. Indian population in general is prone to develop owing to its unhealthy life style, genetic makeup among other factors. Our study too gave us the picture which was similar as only $70 \%$ of our participants were doing exercise that too after re-counselling. We encountered patients having pain of long durations like other studies. $(13,14)$

The goal of 'Neuro dynamic techniques" was believed to be achieved by this method via repeated nerve root stretching and relaxation. The lumbar nerve root stretching using our technique was simple, easy to be selfemployed and home based. This could have been a reason for good prognosis in our study as results suggested, because poor compliance is always major limiting factor in chronic illness. We gave our exercise which was based on a sustainable model of using only proper positioning and specific movements around knee and ankle. The movements and position of exercise were explained to the participants and any queries were addressed so that they can practice the process in their respective homes. Like in other studies we also saw the benefits of supervised exercise therapy $(18,19,20)$ As in other studies mentioned we used our OPD schedule visits and attendants of the participants to regularly follow them whether they were following the exercise and rest pattern as told. After first 15 days they were told to come back and report any problems, improvements and were motivated so that they can continue the schedule of exercise in their homes. They 

were again told to come back in OPD after 30-35 days of sustained activity. Other studies too have used the Visual Analogue Measuring Scale and Oswestry Mobility Index to measure the final outcome and compare the initial scores. $(16,18,19)$

The results also showed the importance of rest along with exercise. However anti-inflammatory and neuropathic pain suppressants drugs along with vitamins supplementation had also been used as per need of the patients. Thus the outcome achieved cannot be fully contributed to exercise and rest. The outcome was also significant in chronic cases who had taken more than one course of medicines before attending our OPD and this supports the effectiveness of approach in chronic lumbar disc disease.

\section{Conclusion}

This study encouraged us to promote means for local folks which are cost effective, sustainable and easy to use. In our study we saw great results as almost all had improvement in their mobility and reduced pain after adhering to our exercise schedule. The participants were enthusiastic as the contraption provided by us were there with them and they didn't need to buy any new thing. This encouraging result further motivates us to conduct similar study on larger number of participants and if feasible promote this in rural hinterlands to the last mile population who are still suffering from the lumbar disc disease as they are bound to do heavy works.

\section{Recommendation}

Any intervention which is sustainable and having an out of pocket expense which is near zero ought to have huge ramifications in chronic diseases. Our intervention meets these two criterions and is effective against a chronic diseases which limits the mobility and drastically reduces the quality of life which results in DALY losses. Further research in these directions will validate the findings of its effectiveness. Once the intervention is thus validated and employed in the majority of the population living with chronic pain and major mobility limitations it is but obvious that the intervention will be boon for all such afflicted individuals. The intervention can thus be termed as one major contributor of the GDP in the state as it would be improving the GDP markedly by reducing the DALY Losses.

\section{Limitation of the study}

The major drawback of this study is as the maneuver is self-employed and home based chances errors were high. We have to rely on patient's statement and many of our patients came from low socioeconomic status and were illiterate. The outcome of this approach highly dependent on other factors as for example general back care, occupational factors, bed rest and drugs.

\section{Relevance of the study}

As there is no such study done on any intervention employed to reduce the chronic pain in lumbar disc disease in Jharkhand or Bihar, its neighboring state. Even on searching the various data bases like PubMed, SCOPUS, EMBASE etc. authors were not able to find any interventions which is so sustainable and using home based intervention modalities being employed in Indian scenario.

\section{Authors Contribution}

AC: Contributed in the Concept, Treatment, Data Storage, Data Entry, Manuscript Writing; RKR: Study design, Data entry, Data Cleaning, Data Analysis, Manuscript Writing, and final editing.

\section{References}

1. Bono CM, Wisneski R, Garfin SR. Lumbar disc herniations. In:Herkowitz HN, Garfin SR, Eismont FJ, Bell GR, Balderston RA, editors. The Spine. 5th ed. Philadelphia, PA: Saunders; 2006.

2. McCulloch JA, Edwards CC II, Riew KD. Lumbar microdiscectomy. In: Bradford DS, Zdeblick TA, editors. Master Techniques in OrthopaedicSurgery: The Spine. Philadelphia, PA: Lippincott Williams \& Wilkins.

3. Carragee E. Surgical treatment of lumbar disk disorders. JAMA. 2006 Nov 22;296(20):2485-7. doi: 10.1001/jama.296.20.2485. PubMed PMID: 17119147.[PubMed].

4. Majlesi J, Togay H, Unalan H, Toprak S. The sensitivity and specificity of the Slump and the Straight Leg Raising tests in patients with lumbar disc herniation. J Clin Rheumatol. 2008 Apr;14(2):8791. doi: 10.1097/RHU.0b013e31816b2f99. PubMed PMID: 18391677. [PubMed].

5. Levangie PK. Association of low back pain with self-reported risk factors among patients seeking physical therapy services. Phys Ther. 1999 Aug;79(8):757-66. PubMed PMID: 10440662.[PubMed].

6. Miyamoto M, Shirai Y, Nakayama Y, Gembun Y, Kaneda K. An epidemiologic study of occupational low back pain in truck drivers. J Nippon Med Sch. 2000 Jun;67(3):186-90. doi: 10.1272/jnms.67.186. PubMed PMID: 10851352.[PubMed].

7. Vingård $E$, Alfredsson $L$, Hagberg $M$, Kilbom $A$, Theorell $T$, Waldenström M, Hjelm EW, Wiktorin C, Hogstedt C. To what extent do current and past physical and psychosocial occupational factors explain care-seeking for low back pain in a working population? Results from the Musculoskeletal Intervention Center-Norrtälje Study. Spine (Phila Pa 1976). 2000 Feb 15;25(4):493-500. doi: 10.1097/00007632-200002150-00017. PubMed PMID: 10707397.[PubMed].

8. Wells R, Moore A, Potvin J, Norman R. Assessment of risk factors for development of work-related musculoskeletal disorders (RSI). Appl Ergon. 1994 Jun;25(3):157-64. doi: 10.1016/00036870(94)90013-2. PubMed PMID: 15676963.[PubMed].

9. Nachemson A, Elfström G. Intravital dynamic pressure measurements in lumbar discs. A study of common movements, maneuvers and exercises. Scand J Rehabil Med Suppl. 1970;1:1-40. PubMed PMID: 4257209.[PubMed].

10. Kuppuswamy Sasi,GeorgeJames C and ChemmanamMili,Prevalence of lumbar disc herniation and disc degeneration in asymptomatic Indian subjects: An MRI based study. IJOS 2017; 3(4): 357-360 (C) 2017 IJOS.

11. Lequin $M B$, Verbaan $D$, Jacobs $W C$, Brand R, Bouma GJ, Vandertop WP, Peul WC. Surgery versus prolonged conservative treatment for sciatica: 5-year results of a randomised controlled trial. BMJ Open. 2013 May 28;3(5). doi: 10.1136/bmjopen-2012-002534. PubMed PMID: 23793663; PubMed Central PMCID: PMC3657649.[PubMed]. 
INDIAN JOURNAL OF COMMUNITY HEALTH / VOL 32 / ISSUE NO 02 / APR - JUN 2020

12. Lee $\mathrm{JH}, \mathrm{Kim} \mathrm{TH}$. The treatment effect of hamstring stretching and nerve mobilization for patients with radicular lower back pain. J Phys Ther Sci. 2017 Sep;29(9):1578-1582. doi: 10.1589/jpts.29.1578. Epub 2017 Sep 15. PubMed PMID: 28931991; PubMed Central PMCID: PMC5599824.[PubMed].

13. Gladson R. B, Taciane S. S, Danilo L. T, AdrianoP. C, Alberito R. C 2009: Neural mobilization andstatic stretching in an experimental sciatica model- an experimental study. RevistaBrasileirade Fisioterapia; 13 .

14. R Prasad, M Hoda, M Dhakal, K Singh, A Srivastava, V Sharma. Epidemiological Characteristics Of Lumbar Disc Prolapse In A Tertiary Care Hospital. The Internet Journal of Neurosurgery. 2005 Volume 3 Number 1.

15. World Health Organization, diabetes mellitus fact sheet, number 238, 2002. Available from: http://www.who.int/chp/knowledge/publications/adherence full report. [Last accessed on 2020 April 01].

16. Singh A, Srivastava RK, Deogharia KS, Singh KK. Distribution of ABO and Rh types in voluntary Blood donors in Jharkhand area as a study conducted by RIMS, Ranchi. J Family Med Prim Care. 2016 JulSep;5(3):631-636. doi: 10.4103/2249-4863.197319. PubMed
[Evaluating the Lumbar]... | Chaitanya A et al PMID: 28217596; PubMed Central PMCID: PMC5290773.[PubMed].

17. Kumar P, Das A, Chandra S, Gari M, Keshri US, Kumari K. Serum Triglyceride Lowering Effect of Cilnidipine in Patients With Essential Hypertension. Cardiol Res. 2016 Oct;7(5):173-177. doi 10.14740/cr497w. Epub 2016 Nov 3. PubMed PMID: 28197288; PubMed Central PMCID: PMC5295564.[PubMed]

18. Winters Jan C, Sobel Jan S, Groenier Klaas H, Arendzen Hans J, Jong Betty Meyboom-de. Comparison of physiotherapy, manipulation, and corticosteroid injection for treating shoulder complaints in general practice: randomised, single blind study BMJ 1997; 314 $: 1320$

19. JC Winters, JS Sobel, KH Groenier, HJ Arendzen, Jong B Meyboomde Comparison of physiotherapy, manipulation, and corticosteroid injection for treating shoulder complaints in general practice: randomised, single blind study BMJ, 1997;314(7090):1320-1325. doi:10.1136/bmj.314.7090.1320.

20. Bang MD, Deyle GD. Comparison of supervised exercise with and without manual physical therapy for patients with shoulder impingement syndrome. J Orthop Sports Phys Ther. 2000 Mar;30(3):126-37. doi: 10.2519/jospt.2000.30.3.126. PubMed PMID: 10721508.[PubMed]

\section{Tables}

TABLE 1 DESCRIBING VARIOUS DIFFERENT CORRELATES RELATED TO SOCIOECONOMIC AND REST ALONG WITH EXERCISE PATTERN OF THE PATIENTS.

\begin{tabular}{|c|c|c|c|c|c|c|}
\hline & & & \multicolumn{2}{|c|}{ Sex } & \multirow[t]{2}{*}{ Total } & \multirow[t]{2}{*}{ p value } \\
\hline & & & Male & Female & & \\
\hline \multirow{12}{*}{$\begin{array}{l}\text { Category of } \\
\text { Age } \\
\text { Mean } 35.87 \\
\text { Std. dev } \\
10.27\end{array}$} & \multirow[t]{2}{*}{$10-20$} & Count & 5 & 0 & 5 & \multirow{12}{*}{.042} \\
\hline & & $\%$ & $100.0 \%$ & $0.0 \%$ & $100.0 \%$ & \\
\hline & \multirow[t]{2}{*}{$21-30$} & Count & 15 & 4 & 19 & \\
\hline & & $\%$ & $78.9 \%$ & $21.1 \%$ & $100.0 \%$ & \\
\hline & \multirow[t]{2}{*}{$31-40$} & Count & 12 & 10 & 22 & \\
\hline & & $\%$ & $54.5 \%$ & $45.5 \%$ & $100.0 \%$ & \\
\hline & \multirow[t]{2}{*}{$41-50$} & Count & 16 & 5 & 21 & \\
\hline & & $\%$ & $76.2 \%$ & $23.8 \%$ & $100.0 \%$ & \\
\hline & \multirow[t]{2}{*}{$51-60$} & Count & 1 & 1 & 2 & \\
\hline & & $\%$ & $50.0 \%$ & $50.0 \%$ & $100.0 \%$ & \\
\hline & \multirow[t]{2}{*}{$61-70$} & Count & 1 & 0 & 1 & \\
\hline & & $\%$ & $100.0 \%$ & $0.0 \%$ & $100.0 \%$ & \\
\hline \multirow[t]{6}{*}{ Address } & \multirow[t]{2}{*}{ Ranchi } & Count & 26 & 8 & 34 & \multirow{6}{*}{.032} \\
\hline & & $\%$ & $76.5 \%$ & $23.5 \%$ & $100.0 \%$ & \\
\hline & \multirow[t]{2}{*}{ Outside Ranchi } & Count & 21 & 11 & 32 & \\
\hline & & $\%$ & $65.6 \%$ & $34.4 \%$ & $100.0 \%$ & \\
\hline & \multirow[t]{2}{*}{ Outside State } & Count & 3 & 1 & 4 & \\
\hline & & $\%$ & $75.0 \%$ & $25.0 \%$ & $100.0 \%$ & \\
\hline \multirow[t]{4}{*}{ Diagnosis } & \multirow{2}{*}{$\begin{array}{l}\text { Lumbar Disc } \\
\text { Disease }\end{array}$} & Count & 49 & 17 & 66 & \multirow{4}{*}{.041} \\
\hline & & $\%$ & $74.2 \%$ & $25.8 \%$ & $100.0 \%$ & \\
\hline & \multirow{2}{*}{$\begin{array}{l}\text { LDD Plus Antero } \\
\text { Lysthesis }\end{array}$} & Count & 1 & 3 & 4 & \\
\hline & & $\%$ & $25.0 \%$ & $75.0 \%$ & $100.0 \%$ & \\
\hline \multirow[t]{9}{*}{ Occupation } & \multirow[t]{2}{*}{ House Wife } & Count & 5 & 10 & 15 & \multirow{9}{*}{.032} \\
\hline & & $\%$ & $33.3 \%$ & $66.7 \%$ & $100.0 \%$ & \\
\hline & \multirow[t]{2}{*}{ Army } & Count & 7 & 1 & 8 & \\
\hline & & $\%$ & $87.5 \%$ & $12.5 \%$ & $100.0 \%$ & \\
\hline & \multirow[t]{2}{*}{ Farmer } & Count & 4 & 3 & 7 & \\
\hline & & $\%$ & $57.1 \%$ & $42.9 \%$ & $100.0 \%$ & \\
\hline & Student & Count & 8 & 2 & 10 & \\
\hline & & $\%$ & $80.0 \%$ & $20.0 \%$ & $100.0 \%$ & \\
\hline & Driver & Count & 10 & 1 & 11 & \\
\hline
\end{tabular}




\begin{tabular}{|c|c|c|c|c|c|c|}
\hline \multicolumn{7}{|c|}{ NDIAN JOURNAL OF COMMUNITY HEALTH / VOL 32 / ISSUE NO 02 / APR - JUN $2020 \quad$ [Evaluating the Lumbar]... | Chaitanya A et al } \\
\hline & & $\%$ & $90.9 \%$ & $9.1 \%$ & $100.0 \%$ & \\
\hline & \multirow[t]{2}{*}{ Police } & Count & 9 & 1 & 10 & \\
\hline & & $\%$ & $90.0 \%$ & $10.0 \%$ & $100.0 \%$ & \\
\hline & \multirow[t]{2}{*}{ Labour } & & 3 & 1 & 4 & \\
\hline & & $\%$ & $75.0 \%$ & $25.0 \%$ & $100.0 \%$ & \\
\hline & \multirow[t]{2}{*}{ Office Work } & Count & 4 & 1 & 5 & \\
\hline & & $\%$ & $80.0 \%$ & $20.0 \%$ & $100.0 \%$ & \\
\hline \multirow{4}{*}{$\begin{array}{l}\text { Exercise day } \\
0\end{array}$} & \multirow[t]{2}{*}{ Yes } & Count & 29 & 11 & 40 & \multirow{4}{*}{0.65} \\
\hline & & $\%$ & $72.5 \%$ & $27.5 \%$ & $100.0 \%$ & \\
\hline & \multirow[t]{2}{*}{ No } & Count & 21 & 9 & 30 & \\
\hline & & $\%$ & $70.0 \%$ & $30.0 \%$ & $100.0 \%$ & \\
\hline \multirow[t]{4}{*}{ Rest (Day 0) } & \multirow[t]{2}{*}{ Yes } & Count & 30 & 12 & 42 & \multirow{4}{*}{0.32} \\
\hline & & $\%$ & $71.4 \%$ & $28.6 \%$ & $100.0 \%$ & \\
\hline & \multirow[t]{2}{*}{ No } & Count & 20 & 8 & 28 & \\
\hline & & $\%$ & $71.4 \%$ & $28.6 \%$ & $100.0 \%$ & \\
\hline
\end{tabular}

TABLE 2 DESCRIPTION OF THE CHRONICITY OF PAIN IN THE PATIENTS ON THE DAY OF EXAMINATION.

\begin{tabular}{|c|c|c|c|c|c|c|}
\hline & & & \multicolumn{2}{|c|}{ Sex } & \multirow[t]{2}{*}{ Total } & \multirow[b]{2}{*}{$p$ value } \\
\hline & & & Male & Female & & \\
\hline \multirow[t]{10}{*}{ Duration in Days } & \multirow[t]{2}{*}{$0-30$} & Count & 39 & 12 & 51 & \multirow{12}{*}{.241} \\
\hline & & $\%$ & $76.5 \%$ & $23.5 \%$ & $100.0 \%$ & \\
\hline & \multirow[t]{2}{*}{$31-90$} & Count & 10 & 5 & 15 & \\
\hline & & $\%$ & $66.7 \%$ & $33.3 \%$ & $100.0 \%$ & \\
\hline & \multirow[t]{2}{*}{$91-180$} & Count & 1 & 0 & 1 & \\
\hline & & $\%$ & $100.0 \%$ & $0.0 \%$ & $100.0 \%$ & \\
\hline & \multirow[t]{2}{*}{$181-365$} & Count & 0 & 2 & 2 & \\
\hline & & $\%$ & $0.0 \%$ & $100.0 \%$ & $100.0 \%$ & \\
\hline & \multirow[t]{2}{*}{$731-1500$} & Count & 0 & 1 & 1 & \\
\hline & & $\%$ & $0.0 \%$ & $100.0 \%$ & $100.0 \%$ & \\
\hline \multirow{2}{*}{\multicolumn{2}{|c|}{ Total }} & Count & 50 & 20 & 70 & \\
\hline & & $\%$ & $71.4 \%$ & $28.6 \%$ & $100.0 \%$ & \\
\hline
\end{tabular}

TABLE 3 A PAIRED SAMPLE T TEST FOR ASSESSING THE MOBILITY OF THE PATIENTS BEFORE OUR INTERVENTION (DAY O SCORES), AFTER 15 DAYS OF OUR INTERVENTION (DAY 15 SCORES) AND AFTER 30 DAYS OF OUR INTERVENTION.

\begin{tabular}{|c|c|c|c|c|c|c|c|c|c|}
\hline \multicolumn{10}{|c|}{ Paired Samples Statistics } \\
\hline & & & & \multicolumn{2}{|c|}{ Mean } & \multicolumn{2}{|c|}{$\mathbf{N}$} & Std. Deviation & Std. Error Mean \\
\hline \multirow[t]{2}{*}{ Pair 1} & \multicolumn{3}{|c|}{ Oswestry Disability Index Day 0} & \multicolumn{2}{|c|}{35.786} & \multicolumn{2}{|c|}{70} & 5.5973 & .6690 \\
\hline & \multicolumn{3}{|c|}{ Oswestry Disability Index Day 15} & \multicolumn{2}{|c|}{20.257} & \multicolumn{2}{|c|}{70} & 7.5213 & .8990 \\
\hline \multirow[t]{2}{*}{ Pair 2} & \multicolumn{3}{|c|}{ Oswestry Disability Index Day 0} & \multicolumn{2}{|c|}{35.786} & \multicolumn{2}{|c|}{70} & 5.5973 & .6690 \\
\hline & \multicolumn{3}{|c|}{ Oswestry Disability Index Day 30} & \multicolumn{2}{|c|}{8.443} & \multicolumn{2}{|c|}{70} & 6.4956 & .7764 \\
\hline & & \multicolumn{6}{|c|}{ Paired Differences } & \multirow[t]{3}{*}{$\mathbf{t}$} & \multirow[t]{3}{*}{ Sig. (2-tailed) } \\
\hline & & \multirow[t]{2}{*}{ Mean } & \multirow[t]{2}{*}{$\begin{array}{l}\text { Std. } \\
\text { Deviation }\end{array}$} & \multirow{2}{*}{$\begin{array}{l}\text { Std. } \\
\text { Error } \\
\text { Mean }\end{array}$} & \multicolumn{3}{|c|}{$\begin{array}{l}\text { 95\% Confidence Interval of } \\
\text { the Difference }\end{array}$} & & \\
\hline & & & & & & & & & \\
\hline \multicolumn{2}{|c|}{$\begin{array}{l}\text { Oswestry Disability } \\
\text { Index Day } 0 \text { - } \\
\text { Oswestry Disability } \\
\text { Index Day } 15\end{array}$} & 15.5286 & 8.1769 & .9773 & & & & 15.889 & .000 \\
\hline \multicolumn{2}{|c|}{$\begin{array}{l}\text { Oswestry Disability } \\
\text { Index Day } 0 \text { - } \\
\text { Oswestry Disability } \\
\text { Index Day } 35\end{array}$} & 27.3429 & 8.4817 & 1.0138 & & & & 26.972 & .000 \\
\hline
\end{tabular}


TABLE 4 A PAIRED SAMPLE T TEST FOR ASSESSING THE MOBILITY OF THE PATIENTS BEFORE OUR INTERVENTION (DAY O SCORES), AFTER 15 DAYS OF OUR INTERVENTION (DAY 15 SCORES) AND AFTER 30 DAYS OF OUR INTERVENTION.

\begin{tabular}{|l|l|l|l|l|l|l|}
\hline \multicolumn{7}{|c|}{ Paired Samples Statistics } \\
\hline
\end{tabular}

TABLE 5 BINARY LOGISTIC REGRESSION TO SEEK PREDICTORS FOR IMPROVEMENT IN PAIN AND PREDICTORS FOR IMPROVEMENT IN MOBILITY

\begin{tabular}{|c|c|c|c|c|c|c|c|}
\hline & & B & S.E. & Wald & df & Sig. & $\operatorname{Exp}(B)$ \\
\hline \multirow{7}{*}{$\begin{array}{l}\text { Predictors for } \\
\text { Improvement in } \\
\text { pain after } 35 \\
\text { days of } \\
\text { Intervention }\end{array}$} & Constant & -3.106 & .590 & 27.703 & 1 & .000 & .045 \\
\hline & Exercise after day15* & -34.63 & 4.794 & 1 & 1 & .029 & 4.451 \\
\hline & Rest after day15* & -25.457 & 4.794 & 1 & 1 & .029 & 1.066 \\
\hline & Exercise after day35 & 82.576 & 3.514 & 1 & 1 & .061 & .000 \\
\hline & Rest after day35 & 20.558 & 3.514 & 1 & 1 & .061 & .000 \\
\hline & VisualAnalogueScaleDay0* & -7.668 & 7.695 & 1 & 1 & .006 & 4.451 \\
\hline & OswestryDisabilityIndexDay0* & -4.423 & 7.251 & 1 & 1 & .007 & 1.066 \\
\hline \multicolumn{2}{|l|}{ Constant } & B & S.E & Wald & df & Sig. & $\operatorname{Exp}(B)$ \\
\hline \multirow{10}{*}{$\begin{array}{l}\text { Predictors for } \\
\text { improvement in } \\
\text { Mobility after } \\
35 \text { days of } \\
\text { Intervention }\end{array}$} & Sex & -.579 & 2.943 & .039 & 1 & .844 & .560 \\
\hline & Age & -.108 & .119 & .813 & 1 & .367 & .898 \\
\hline & Duration in days & .007 & .008 & .704 & 1 & .402 & 1.007 \\
\hline & Exercise after day15* & -25.220 & 5039.619 & .000 & 1 & .996 & .000 \\
\hline & Rest after day15* & -22.266 & 5422.515 & .000 & 1 & .997 & .000 \\
\hline & Exercise after day35 & 27.705 & 5039.621 & .000 & 1 & .996 & 1076.940 \\
\hline & Rest after day35 & .529 & 2.074 & .065 & 1 & .799 & 1.698 \\
\hline & VisualAnalogueScaleDay0* & 1.733 & 2.803 & .382 & 1 & .536 & 5.656 \\
\hline & OswestryDisabilityIndexDay0* & -.686 & .674 & 1.036 & 1 & .309 & .503 \\
\hline & Constant & 31.842 & 5422.540 & .000 & 1 & .995 & 7.95 \\
\hline
\end{tabular}

